\title{
Aromatic Pathways in Porphycene Derivatives Based on Current-Density Calculations
}

\section{Benkyi, Isaac}

2019-01-10

Benkyi , I \& Sundholm , D 2019 , ' Aromatic Pathways in Porphycene Derivatives Based on Current-Density Calculations ', Journal of Physical Chemistry A, vol. 123 , no. 1 , pp. pÿ284 292 . https://doi.org/10.1021/acs.jpca.8b10818

http://hdl.handle.net/10138/309464

https://doi.org/10.1021/acs.jpca.8b10818

unspecified

acceptedVersion

Downloaded from Helda, University of Helsinki institutional repository.

This is an electronic reprint of the original article.

This reprint may differ from the original in pagination and typographic detail.

Please cite the original version. 


\title{
Aromatic Pathways in Porphycene Derivatives
}

\section{Based on Current-Density Calculations}

\author{
Isaac Benkyi and Dage Sundholm* \\ University of Helsinki, Department of Chemistry, P.O. Box 55 (A.I. Virtanens plats 1), \\ FIN-00014 University of Helsinki, Finland \\ E-mail: Dage.Sundholm@helsinki.fi
}




\begin{abstract}
Magnetically induced current densities have been calculated for porphycenes at the density functional theory (DFT) level using gauge-including atomic orbitals to ensure gauge-origin independence and a fast basis-set convergence of the current densities. The current densities have been analyzed by using the gauge-including magnetically induced current (GIMIC) method. The porphycenes are aromatic sustaining strong diatropic ring currents. The ring-current pathways have been determined by integrating the strength of the current density passing selected bonds. The calculations show that the ring current of the porphycenes splits into an outer and inner branch at the pyrrolic rings implying that the ring current involves all $26 \pi$ electrons of the porphycenes, which is similar to the ring current of porphyrins. The pyrrolic rings of the aromatic porphycenes do not sustain any significant local ring currents. Dihydroporphycene with four inner hydrogens is antiaromatic with weakly aromatic pyrrolic rings. The annelated benzoic rings in benzoporphycene sustain local paratropic ring-currents, whereas the global ring current of dibenzoporphycene splits into an outer and inner branch at the benzoic rings. Comparison of calculated ${ }^{1} \mathrm{H}$ NMR shieldings with ringcurrent strengths shows that interactions between the inner hydrogen and the neighbor nitrogen is more significant for differences in the ${ }^{1} \mathrm{H}$ NMR shieldings than variations in global ring-current strengths. Calculated excitation energies show that the antiaromatic dihydroporphycene has a smaller optical gap than the aromatic porphycene, even though its HOMO-LUMO gap is larger.
\end{abstract}

\title{
1 Introduction
}

Vogel et al. performed systematic studies of novel kinds of aromatic porphyrin structures in the mid-1980s, which led to the discovery of porphycene. ${ }^{1}$ Porphycenes are a class of compounds that is reminiscent of porphyrin with four linked pyrrolic rings forming a central 16-membered macroring and an outer annulene ring with $20 \pi$ electrons. Waluk et al. showed later that the electronic structure and the aromatic properties of porphycenes can 
be understood by using the perimeter model for the outer $\mathrm{C}_{20} \mathrm{H}_{20}{ }^{2+}$ macroring fulfilling Hückel's aromaticity rule. ${ }^{2}$ The porphycene chemistry has later been extended to synthesis of more general porphycene-like structures such as corrphycene, hemiporphycene, and isoporphycene, ${ }^{2-7}$ which have the same length of conjugation pathways as porphycene. Porphycene chemistry is still today a very active research field, because porphycene and porphycene derivatives can be used in many applications such as sensitizers for photodynamic therapy, in catalysis, and as dyes in solar cells, etc. ${ }^{8-13}$ Porphycenes form stable metal complexes that can be used in different contexts. ${ }^{14-16}$ Porphycene has also been suggested to be the most stable of all porphyrin-like isomers, because of its rectangular cavity with four inner nitrogens and two inner hydrogens that can form strong intramolecular hydrogen bonds. ${ }^{17-19}$

The aromatic properties of porphycenes have been studied experimentally by ${ }^{1} \mathrm{H}$ NMR spectroscopy ${ }^{20}$ and computationally by calculating aromatic stabilization energies, ${ }^{20,21}$ magnetic shielding functions, ${ }^{21-23}$ and magnetically induced current densities. ${ }^{21-25}$ Optical spectroscopy measurements ${ }^{16,22}$ and graph-theoretical methods ${ }^{26}$ have also been used for assessing aromatic properties of porphycenes. Spectroscopic and aromatic properties of porphycenes have recently been reviewed. ${ }^{13,27}$

Vogel et al. suggested in the 1990s that porphycenes have a similar [18] $\pi$ aromatic pathway as the classical aromatic pathway of porphyrins, ${ }^{14}$ where the aromatic pathway is not considered to pass the ethylidene $(\mathrm{C}=\mathrm{C})$ bridges of the pyrrolic rings without an inner hydrogen and the inner $\mathrm{NH}$ groups of the pyrrolic rings do not belong to the aromatic pathway. More recently one has discovered that at least the $22 \pi$ electrons of the 11 conjugated bonds have to be considered in order to obtain the correct description of the magnetic properties of freebase porphyrin. ${ }^{28}$ Steiner and Fowler, ${ }^{24}$ who performed explicit current density calculations, suggested that the current density of porphycene consists of a distinct single delocalization pathway that bifurcates at the four pyrrolic rings. Extensive ring-current strength studies on different porphyrinoids show that the bifurcation of the diatropic current pathways occurs in practically all aromatic porphyrinoids. ${ }^{29-34}$ The strength of the current pathway passing the 
inner hydrogen is weaker than the one passing the ethylidene bridge of the same pyrrolic ring, whereas at the pyrrolic rings without an inner hydrogen the current density is divided almost equally along the two branches. ${ }^{29}$ Explicit current density calculations and integration of the current strengths passing different chemical bonds show unambiguously that the individual pyrrolic rings do not sustain any significant local ring currents. ${ }^{35}$ Thus, a better description of the aromatic properties of free-base porphyrin is obtained when considering that the $26 \pi$

electrons of all conjugated bonds contribute to the aromatic pathway. ${ }^{29,36,37}$ Antiaromatic porphyrinoids are dominated by a strong paratropic current inside the porphyrinoid rings that extends towards the exterior of the molecule. ${ }^{34,38-40}$

In this work, we have optimized the molecular structures of eleven porphycenes and one dihydroporphycene and calculated ring-current strengths and current pathways in order to obtain deeper insights about the aromatic properties of porphycenes. The employed computational methods and obtained molecular structures are described in Section 2. The calculated ring-current strengths and current pathways are presented in Section 3. The main results are summarized and discussed in Section 4.

\section{Computational Methods}

\subsection{Structure Optimization}

The molecular structures were optimized at the density functional theory (DFT) level using Becke's three-parameter functional (B3LYP) ${ }^{41-43}$ with Grimme's D3-BJ dispersion correction $^{44}$ and the Karlsruhe triple- $\zeta$ quality basis sets (def2-TZVP). ${ }^{45}$ Porphycene was also optimized using the same basis sets and the Minnesota global hybrid functional with $54 \%$ Hartree-Fock exchange (M06-2X) ${ }^{46}$ and the Becke-Half-and-Half-LYP (BHLYP) hybrid functional. ${ }^{47}$ All calculations were done with Turbomole version 7.1 program package. ${ }^{48,49}$ The carbon-carbon and carbon-nitrogen bond lengths of the porphycene molecule optimized using different functionals are compared with available experimental data. ${ }^{1}$ The comparison show 
that the root mean square (RMS) deviations for the $\mathrm{C}-\mathrm{C}$ and $\mathrm{C}-\mathrm{N}$ bonds are $0.011,0.012$ and $0.010 \AA$ for B3LYP, BHLYP and M06-2X, respectively, which shows that the molecular structures optimized at the different levels of theory are almost identical.

\subsection{Molecular Structures and Nomenclature}

Porphycene (I) is a planar molecule that belongs to the $C_{2 \mathrm{~h}}$ point group. It has two adjacent pyrrolic rings which are directly connected via their $\alpha$ - and $\alpha^{\prime}$-carbons, while the $\alpha$ - and $\alpha^{\prime}$-carbons of the other pyrrolic rings are connected via ethylidene $(-\mathrm{HC}=\mathrm{CH}-)$ groups. The labeling of carbon atoms and pyrrolic rings are shown in Figure 1.

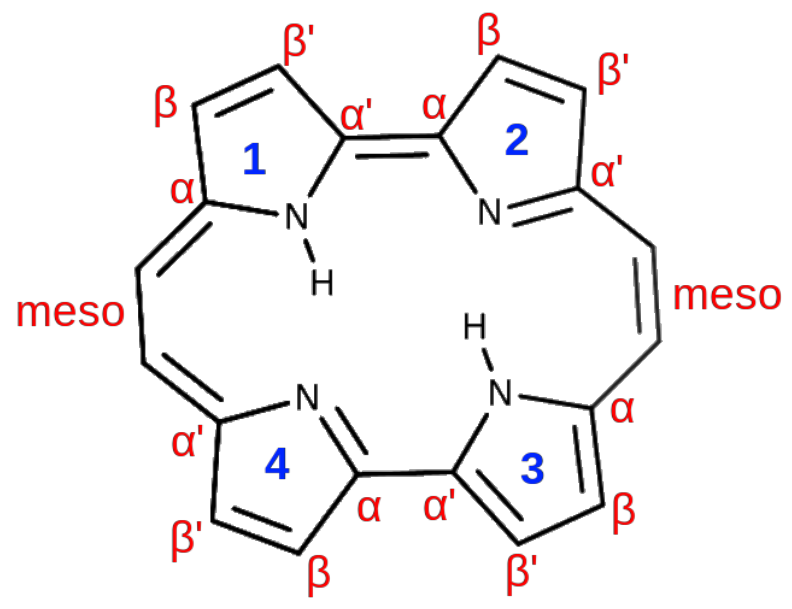

Figure 1: Atom labeling and ring numbering of the porphycene molecule. The figure has been made with Marvinsketch $18.25^{50}$ and GIMP 2.8.22. ${ }^{51}$

The Z-configuration of the meso ethylidene moiety has lower energy than the E-configuration, which can also be expected due to steric effects. ${ }^{18}$ The inner hydrogens can have a trans or a cis configuration. The calculations show that the trans configuration is $2.7 \mathrm{kcal} / \mathrm{mol}$ below the cis conformer and that they are separated by a transition barrier of $5.0 \mathrm{kcal} / \mathrm{mol}$. The transition barrier is much lower than for porphyrins suggesting that there is indeed a strong interaction between the nitrogen and the hydrogen of the adjacent NH group. ${ }^{52-55}$ The molecular structure of porphycene $(\mathbf{I})$ is shown in Figure 2a. Dihydroporphycene (II) 
shown in Figure $2 \mathrm{~b}$ has four inner hydrogens to the nitrogens of the pyrrolic rings. It has a saddle structure with the inner hydrogens pointing out from the porphycene ring due to steric effects.

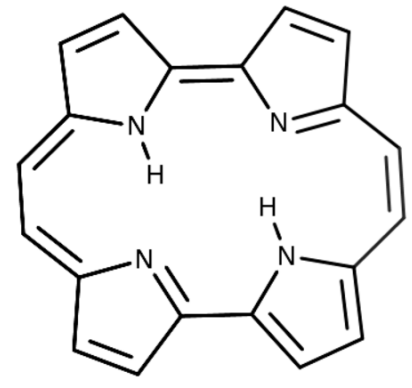

(a)

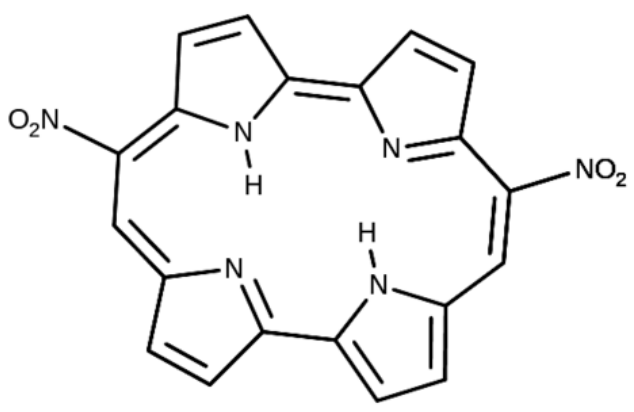

(c)

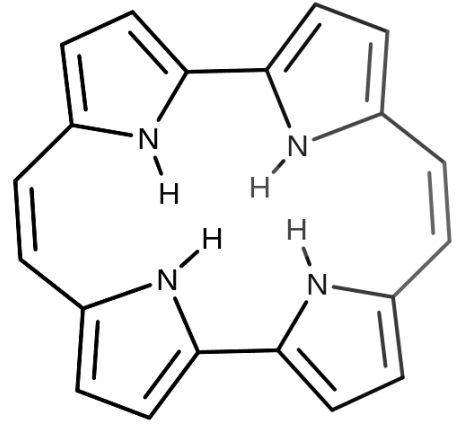

(b)

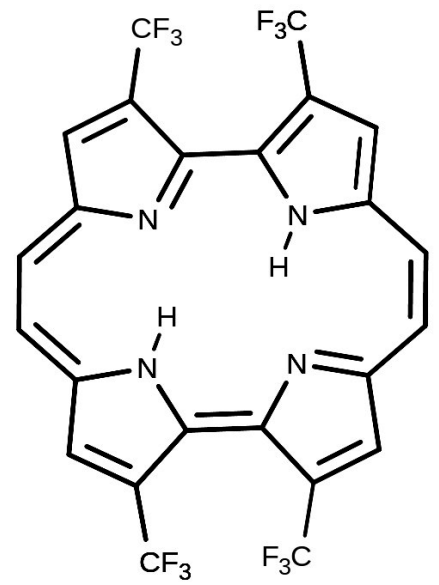

(d)

Figure 2: The molecular structure of (a) porphycene (I), (b) dihydroporphycene (II) (c) dinitroporphycene (III), and (d) fluoroporphycene (IV). The figure has been made with Marvinsketch 18.25.

Dinitroporphycene (III) shown in Figure 2c is a meso-dinitro substituted porphycene with a planar porphycene ring that has been synthesized by Anguera et al. ${ }^{27,56}$ The synthesized dinitroporphycene had phenyl substituents at the $\beta$ positions of the four pyrrolic rings, whereas in the calculations we replaced the phenyl groups with hydrogens. The trans conformer of the inner hydrogen is $3.2 \mathrm{kcal} / \mathrm{mol}$ lower in energy than the cis one.

The porphycene ring of fluoroporphycene (IV) shown in Figure 2d is non-planar. The presence of the $\mathrm{CF}_{3}$ groups distort the planarity of the porphycene ring. Molecule IV has 
one trifluoromethyl substituent to each pyrrolic ring. Two of the trifluoromethyl groups are at $\beta$ positions and two at the $\beta^{\prime}$ positions closest to each other. The trans conformer of the inner hydrogens is energetically $3.3 \mathrm{kcal} / \mathrm{mol}$ below the cis structure.

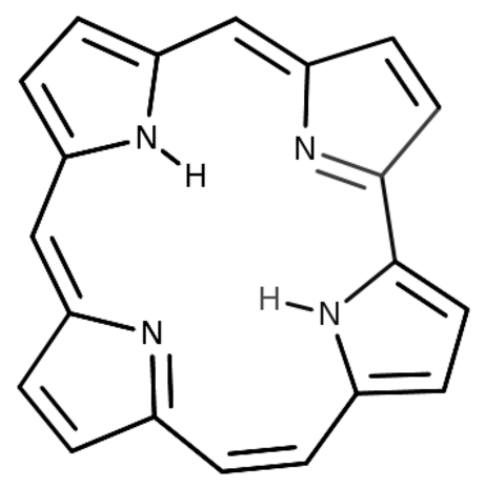

(a)

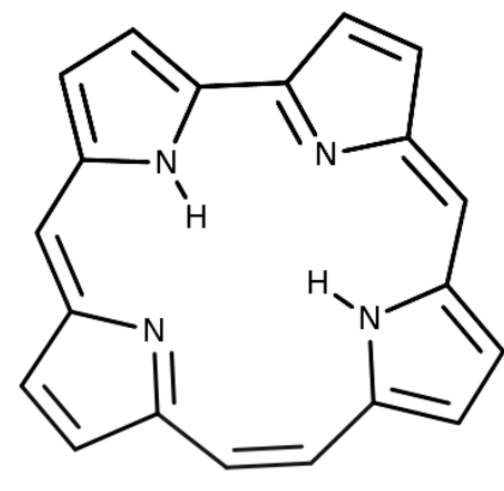

(b)

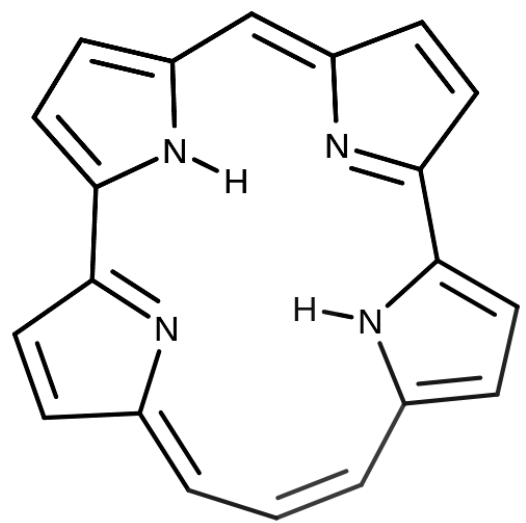

(c)

Figure 3: The molecular structure of (a) hemiporphycene (V), (b) corrphycene (VI), and (c) isoporphycene (VII). The figure has been made with Marvinsketch 18.25.

Hemiporphycene $(\mathbf{V})$ shown in Figure 3a has two methine $(\mathrm{CH})$ groups bridging three of the pyrrolic rings. It has a direct link between the $\alpha^{\prime}$ and $\alpha$ carbons of two pyrrolic rings and a Z-ethylidene $((\mathrm{Z})-\mathrm{CH}=\mathrm{CH}-)$ bridge between the $\alpha$ carbon of two pyrrolic rings. Ostapko et $a l$. recently reported the synthesis and characterization of free-base hemiporphycene. ${ }^{57}$ The calculations show that the trans tautomer shown in Figure 3a has the lowest energy, which is in agreement with previous calculations. ${ }^{18}$

Corrphycene (VI) in Figure 3b has two methine groups linking two pyrrolic rings on the opposite side of the macroring. It has a Z-ethylidene bridge between two of the pyrrolic rings and two pyrrolic rings are directly linked at their $\alpha$ and $\alpha^{\prime}$-carbons. Different corrphycenes have been synthesized. ${ }^{5,58,59} \mathrm{Wu}$ et al. showed that the minimum energy structure is the conformer in which the inner hydrogens are in trans position and the ethylidene moiety has a Z-configuration, which results in a planar molecular structure. ${ }^{18}$

Isoporphycene (VII) in Figure 3c has two direct links between the pyrrolic rings on opposite sides of the porphycene ring. A methine group links two pyrrolic rings and a $-\mathrm{CH}=\mathrm{CH}-\mathrm{CH}=$ group links two pyrrolic rings. The calculations show that the Z-configuration 
of the $-\mathrm{CH}=\mathrm{CH}-\mathrm{CH}=$ group is $7.2 \mathrm{kcal} / \mathrm{mol}$ lower energy than the E-configuration, which agrees with results obtained in previous calculations. ${ }^{60}$ When isoporphycene has ethyl substituents in the $\beta$ and $\beta^{\prime}$ positions, the E-configuration of free-base isoporphycene has slightly lower energy than the Z-configuration. ${ }^{6,18,60}$

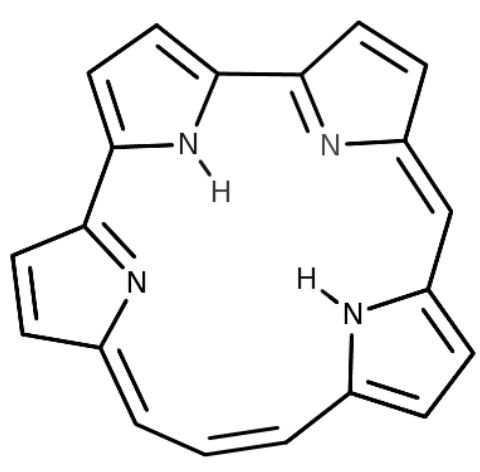

(a)

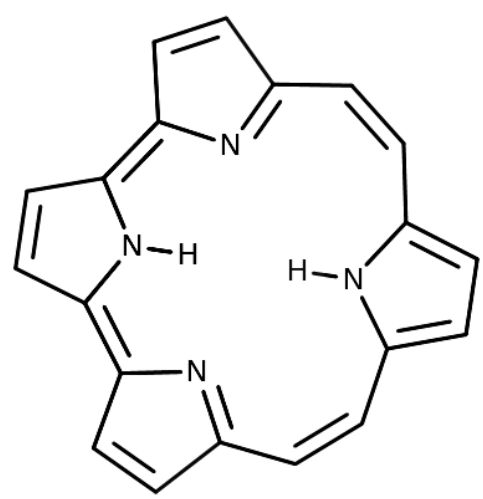

(b)

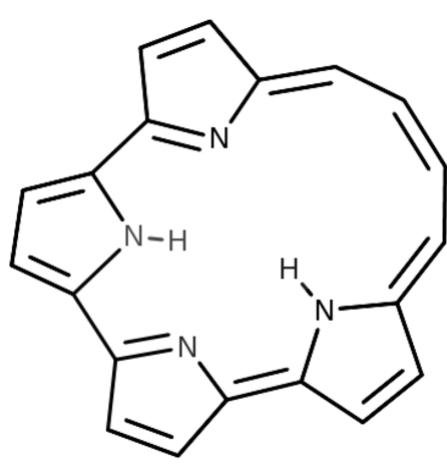

(c)

Figure 4: The molecular structure of the (a) porphyrin (3.0.0.1) VIII, (b)porphyrin (2.0.0.2) IX, and (c) porphyrin (4.0.0.0) X. The figure has been made with Marvinsketch 18.25.

Molecule VIII shown in Figure 4a has a similar structure as isoporphycene. However, in VIII, the two directly-linked pyrrolic rings are next to each other. The two other bridges between pyrrolic rings consist of a methine and a $-\mathrm{C}=\mathrm{CH}-\mathrm{CH}=$ moiety as in VII. The Z-configuration of the $-\mathrm{C}=\mathrm{CH}-\mathrm{CH}=$ group is the energetically lower structure. ${ }^{18}$

Molecule IX shown in Figure 4b has two direct links between three pyrrolic rings and it has two ethylidene bridges connecting three pyrrolic rings at the $\alpha^{\prime}$ - and $\alpha$ positions. The Z-configuration of the ethylidene bridges has the lowest energy. ${ }^{18}$

Molecule $\mathbf{X}$ shown in Figure 4c has pyrrolic rings linked by three direct bridges at the $\alpha$ and $\alpha^{\prime}$ positions. The fourth bridge consists of a $-\mathrm{CH}-\mathrm{CH}=\mathrm{CH}-\mathrm{CH}-$ group. To the best of our knowledge, molecules VIII, IX and $\mathbf{X}$ have not been synthesized.

Molecule XI in Figure 5a is benzoporphycene representing a class of porphycene derivatives that have an extended conjugation pathway due to two benzoic rings that are annelated to the porphycene macrocycle. Several kinds of benzoporphycenes are obtained by adding the benzoic ring at different positions. ${ }^{27,61}$ The synthesis of molecule $\mathbf{X}$ was first reported 


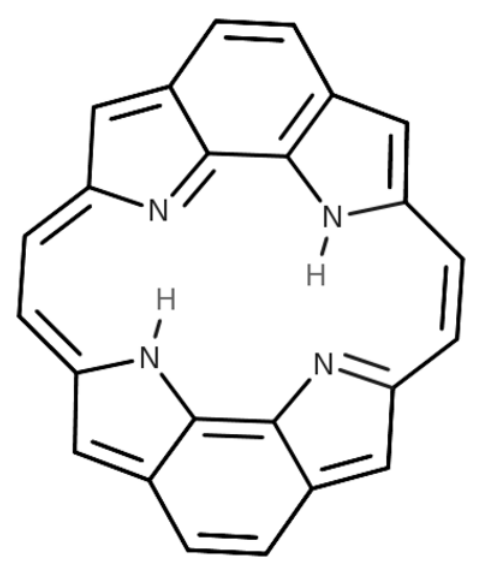

(a)

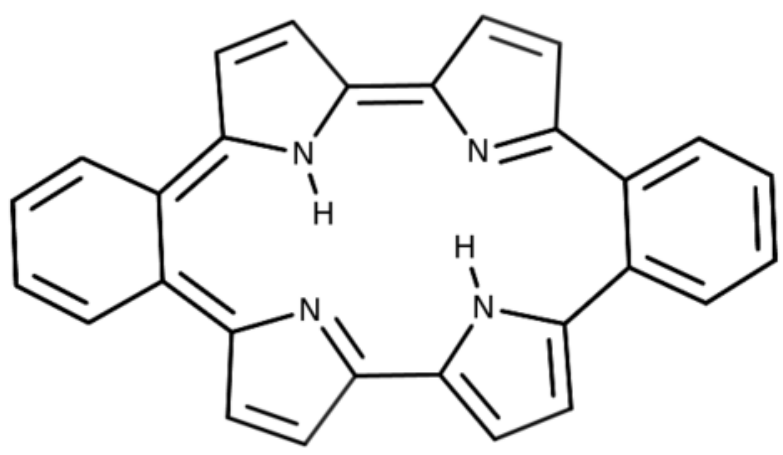

(b)

Figure 5: The molecular structure of (a) benzoporphycene (XI) and (b) dibenzoporphycene (XII). The figure has been made with Marvinsketch 18.25.

by Vogel. ${ }^{14}$ The synthesized benzoporphycene had tert-butyl substituents in the $\beta$ positions, whereas we replaced them with hydrogens in order to save computational time. Many benzoporphycenes have been investigated experimentally and computationally, ${ }^{12-14,27}$ whereas to our knowledge molecule XI has not been previously studied computationally. The calculations show that the trans conformer of the inner hydrogens is $1.8 \mathrm{kcal} / \mathrm{mol}$ below the cis one. The molecular structure of molecule XI is bowl shaped.

Dibenzoporphycene (XII) in Figure 5b is a porphycene derivative with the ethylidene bridges between pyrrolic rings replaced by benzoic rings, which increases the conjugation length. The cis conformer is $0.4 \mathrm{kcal} / \mathrm{mol}$ below the trans one, which is in agreement with previous calculations. ${ }^{62}$ The presence of the two benzoic ring at the meso position distort the planarity of the porphycene moiety.

The atomic coordinates of the molecular structures are given as supporting information $(\mathrm{SI})$. 


\subsection{Methods of Current-Density Calculation}

Current densities were calculated with the open-source GIMIC program. ${ }^{35,63-65}$ The input data for the current density calculations are basis-set information, density matrices and magnetically perturbed density matrices, which are obtained in calculations of nuclear magnetic resonance (NMR) shielding constants. The NMR shielding constants were calculated with Turbomole version 7.1 at the B3LYP/def2-TZVP level using gauge-including atomic orbitals (GIAO) in order to ensure gauge-origin independence and a fast basis-set convergence for the current density. ${ }^{66-68}$ The strength of the current density passing selected chemical bonds was obtained by integrating the current flow passing a plane that intersects the bond perpendicularly in the middle of the bond. ${ }^{63}$ The exact position of the integration plane is not crucial because of the charge conservation of the current density. ${ }^{69}$ Most of the current density passing the bond is taken into account, because the integration plane begins in the center of the ring and ends far outside the molecule. The external magnetic field is applied perpendicularly to the porphycene ring. The current densities obtained with GIMIC can also be visualized. ${ }^{70}$ We use freely available software like ParaView and VMD, ${ }^{71,72}$ whereas many other softwares that visualize vector fields can be employed. GIMP and Jmol were used in this work for creating the current-strength graphics. ${ }^{51,73}$

\section{Current-density calculations}

\subsection{Porphycene, Dihydroporphycene, Dinitroporphycene and Flu- oroporphycene}

Our current density calculations show that porphycenes are aromatic sustaining a strong diatropic ring current. The ring current splits into an inner and an outer pathway at the pyrrolic rings. The inner pathway is weaker when a hydrogen is attached to the pyrrolic nitrogen. 


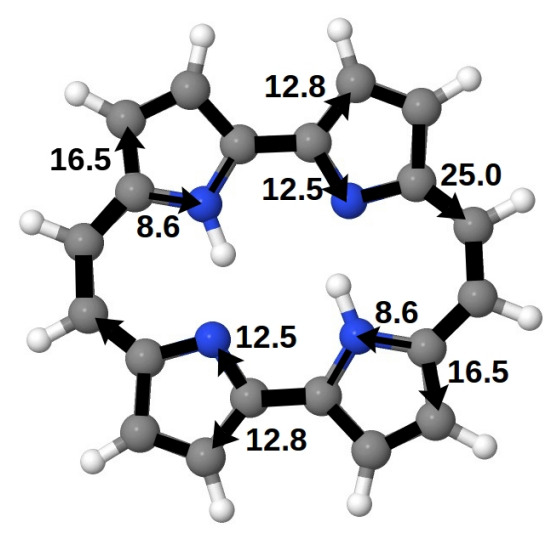

(a)

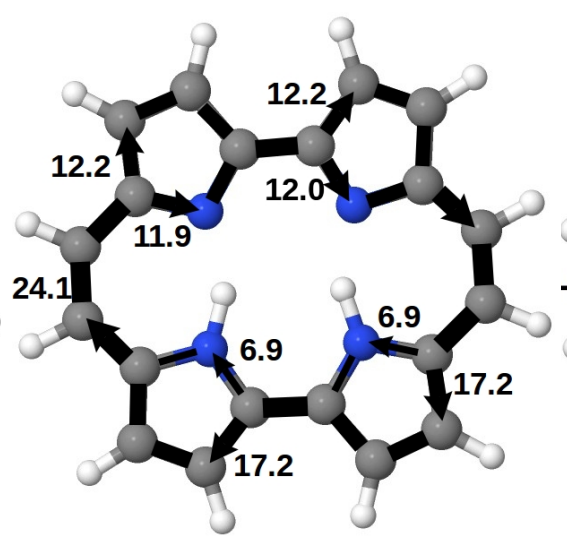

(b)

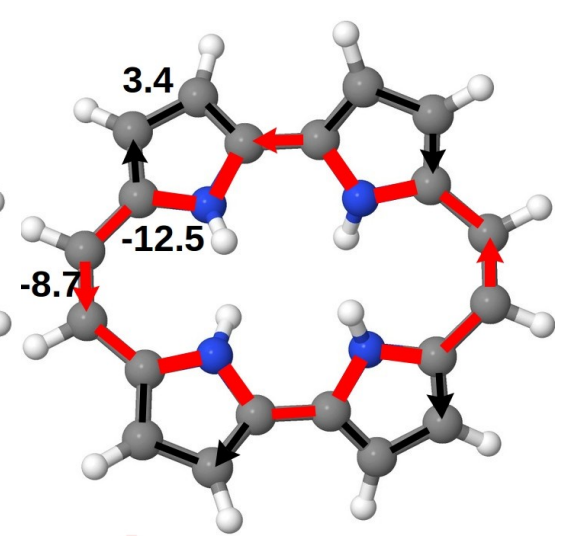

(c)

Figure 6: The calculated ring-current strengths and current pathways in free-base (a) transporphycene (I), (b) cis-porphycene and (c) dihydroporphycene (II). The figure has been made with Jmol 14.6.4 and GIMP 2.8.22. ${ }^{51,73}$

For free-base trans-porphycene the net global ring-current strength is $25 \mathrm{nA} / \mathrm{T}$. Positive ring-current strengths denote diatropic currents. Aromatic molecular rings sustain net diatropic ring currents, whereas paratropic currents have negative current strengths in our notation. At the pyrrolic rings without an inner hydrogen, the ring current splits into two branches of about equal strength. The strengths of the different current pathways of transporphycene (I) are shown in Figure 6a. The strength of the current passing the nitrogen with an inner hydrogen is about half the one passing the $\beta$ carbons. The current strengths of free-base cis-porphycene are shown in Figure 6b. The global ring-current strength of cis-porphycene is $24 \mathrm{nA} / \mathrm{T}$, which is $1 \mathrm{nA} / \mathrm{T}$ weaker than for trans-porphycene. For cisporphycene, the current strengths of the inner and outer routes have the same ratio as for free-base trans-porphycene.

The dihydroporphycene (II) ring is antiaromatic sustaining a net global paratropic current strength of $-9 \mathrm{nA} / \mathrm{T}$. The pyrrolic rings sustain local diatropic ring currents of $3 \mathrm{nA} / \mathrm{T}$. The current strengths and the different current pathways are shown in Figure 6c.

The orbital energy difference of $2.68 \mathrm{eV}$ between the highest-occupied molecular orbital (HOMO) and the lowest-unoccupied molecular orbital (LUMO) for molecule II is larger than the HOMO-LUMO gap of $2.47 \mathrm{eV}$ for molecule $\mathbf{I}$ as also reported previously. ${ }^{22}$ Even though 
the HOMO-LUMO gap is larger for the antiaromatic dihydrogenporphycene (II) than for the aromatic porphycene (I), the excitation energy of the first excited singlet state of 1.99 $\mathrm{eV}$ for molecule II is smaller than the first singlet excitation energy of $2.24 \mathrm{eV}$ for molecule I. The first excited state of $\mathbf{I}$ is dominated by the HOMO-LUMO+1 transition, whereas the first excited state of II is dominated by the HOMO-LUMO transition. Thus, comparisons of HOMO-LUMO gaps might not be completely reliable for assessing molecular stability and aromatic character. The dipole transition to the first excited of molecule $\mathbf{I}$ has a large oscillator strength of 0.13 , whereas the oscillator strength of the first excited singlet state of molecule II is only 0.0003 . The transition to the first excited singlet state of molecule II has a large magnetic transition moment of 4.54. The small oscillator strength and the large magnetic transition moment are typical for antiaromatic molecules. ${ }^{74}$ The excitation energies, magnetic transition moments, and oscillator strengths of molecules I and II were calculated at the time-dependent density functional theory (TDDFT) level using the B3LYP functional and the def2-TZVP basis sets. ${ }^{49,75,76}$

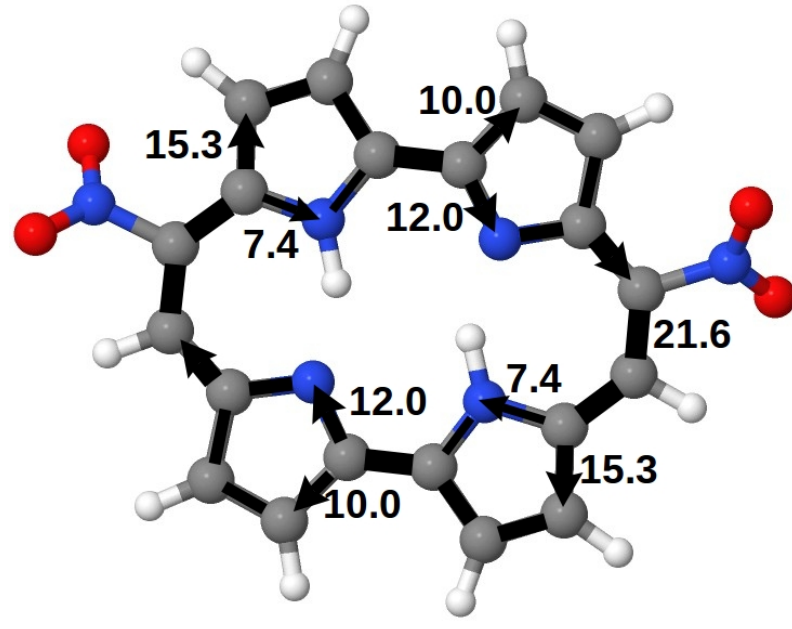

(a)

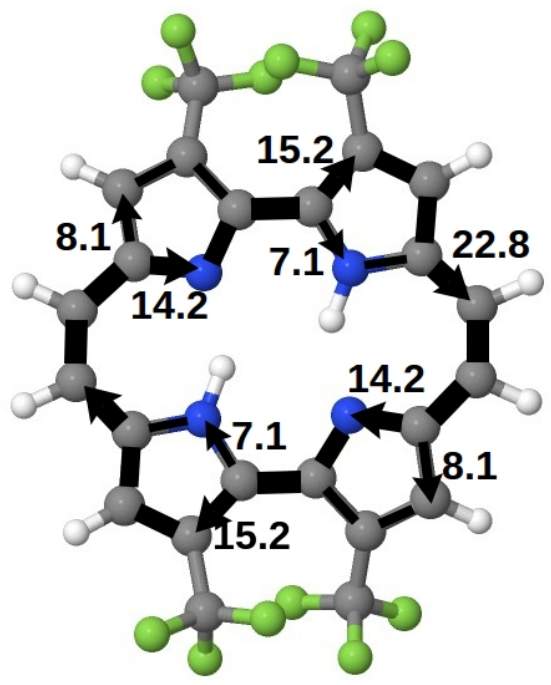

(b)

Figure 7: The calculated ring-current strengths and current pathways of (a) dinitroporphycene (III) and (b) fluoroporphycene (IV). The figure has been made with Jmol 14.6.4 and GIMP 2.8.22. ${ }^{51,73}$

The calculated current strengths of molecules III and IV show how electro-negative 
substituents affect the current density. Molecule III has two nitro groups $\left(-\mathrm{NO}_{2}\right)$ in the meso positions as shown in Figure 7a. The ring-current strength is about $22 \mathrm{nA} / \mathrm{T}$, which is $3 \mathrm{nA} / \mathrm{T}$ weaker than for molecule $\mathbf{I}$. The ring-current pathways are the same as for $\mathbf{I}$, whereas the individual current pathways are weaker than for $\mathbf{I}$.

Molecule IV has trifluoromethyl $\left(\mathrm{CF}_{3}\right)$ groups substituents at the $\beta$ carbons as shown in Figure 7b. It sustains a net ring current of $22 \mathrm{nA} / \mathrm{T}$ showing that the ring-current strength is weaker because the electro-negative substituents remove electrons from the conjugation pathway. The largest effect is obtained for the pyrrolic rings without an inner hydrogen. In molecule $\mathbf{I}$, the ring-current is equally split between the inner and outer pathway, whereas in molecule IV, the current strength of the outer pathway is nearly half the current strength passing via the nitrogen. For the pyrrolic rings with inner hydrogens, the ratio between the current strengths of the inner and the outer pathway is about the same as for $\mathbf{I}$.

\subsection{Hemiporphycene, Corrphycene and Isoporphycene}

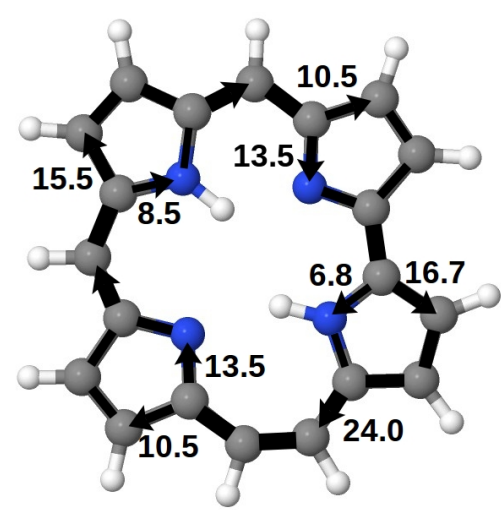

(a)

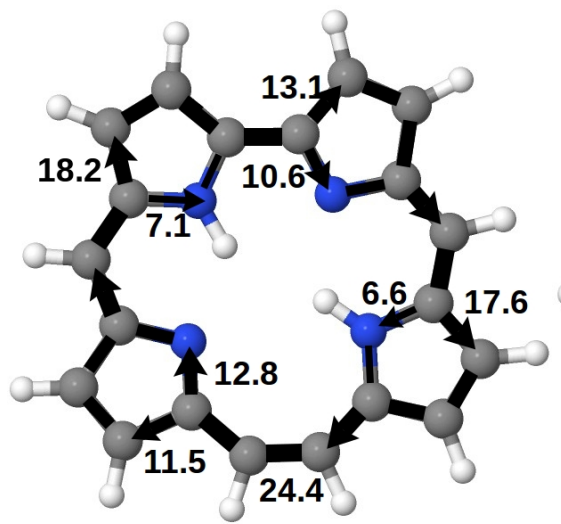

(b)

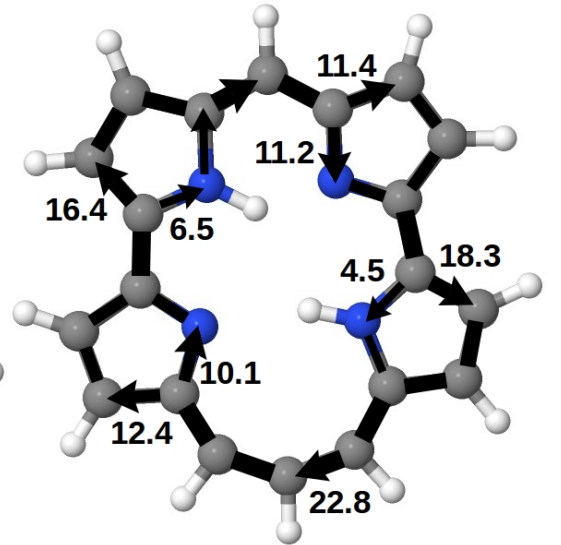

(c)

Figure 8: The calculated ring-current strengths and current pathways for (a) hemiporphycene (V), (b) corrphycene (VI), and (c) isoporphycene (VII). The figure has been made with Jmol 14.6.4 and GIMP 2.8.22. ${ }^{51,73}$

The current strengths and current pathways of hemiporphycene, corrphycene, and isoporphycene are shown in Figure 8. Hemiporphycene (IV) is also aromatic sustaining a net 
diatropic ring-current strength of $24 \mathrm{nA} / \mathrm{T}$, which is only $1 \mathrm{nA} / \mathrm{T}$ smaller than for transporphycene. The ring-current pathways have the same topology as the ones for free-base trans-porphycene. Corrphycene (V) sustains a net ring-current strength of $24 \mathrm{nA} / \mathrm{T}$. The ring-current splits almost equally at the pyrrolic rings without an inner hydrogen, whereas at the pyrrolic rings with an inner hydrogen, the main current flow of about $18 \mathrm{nA} / \mathrm{T}$ takes the outer route. Isoporphycene sustains a net diatropic ring-current of $23 \mathrm{nA} / \mathrm{T}$. It has similar current strengths and current pathways as corrphycene.

\subsection{Molecules VIII, IX and X}

Porphyrin (3.0.0.1) VIII, porphyrin (2.0.0.2) IX, and porphyrin(4.0.0.0) $\mathbf{X}$ are aromatic sustaining global ring currents of $21 \mathrm{nA} / \mathrm{T}, 26 \mathrm{nA} / \mathrm{T}$, and $25 \mathrm{nA} / \mathrm{T}$, respectively. The current strength of the different current pathways have roughly the same topology as for the other studied porphycenes. The ring current splits almost equally at the pyrrolic rings without an inner hydrogen and at the pyrrolic ring with an inner hydrogen the current strength of the inner route is between one third to half of the current that takes the outer route. The current strengths and current pathways are shown in Figure 9.

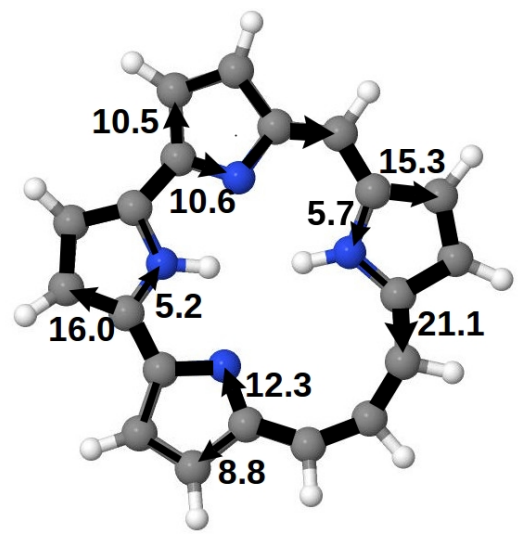

(a)

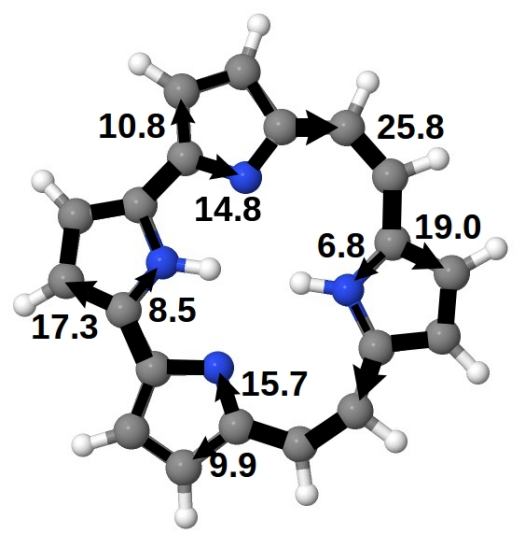

(b)

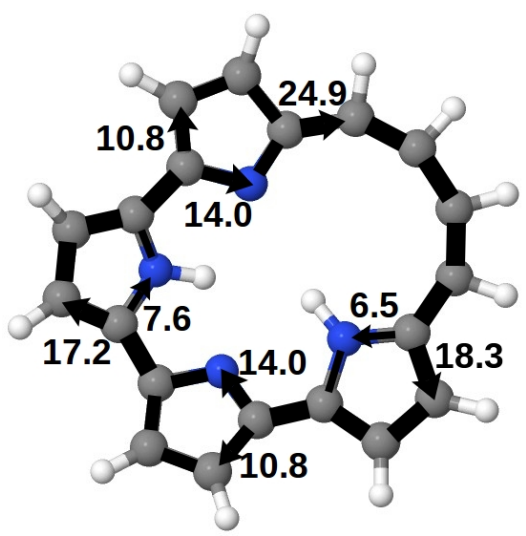

(c)

Figure 9: The calculated ring-current strengths and current pathways for (a) porphyrin (3.0.0.1) VII, (b) porphyrin (2.0.0.2) VIII and (c) porphyrin (4.0.0.0) IX. The figure has been made with Jmol 14.6.4 and GIMP 2.8.22. ${ }^{51,73}$ 


\subsection{Benzoporphycene and Dibenzoporphycene}

Benzoporphycene $(\mathbf{X I})$ is globally aromatic, sustaining a net ring current of $17 \mathrm{nA} / \mathrm{T}$. However, the fused benzoic rings sustain local paratropic ring currents of $-4.5 \mathrm{nA} / \mathrm{T}$. The current strengths of the different current pathways are shown in Figure 10a. The ring current splits at the pyrrolic rings as for the other studied porphycenes. However, the current-strength pattern of XI differs significantly from the rest, because the annelated benzoic rings are antiaromatic. A strong diatropic ring current of $21 \mathrm{nA} / \mathrm{T}$ passes the inner $\mathrm{C}-\mathrm{C}$ bond of the benzoic rings, because the outer route involves $20 \pi$ electrons, whereas the inner one has 18 $\pi$ electrons. Most of the ring current takes the inner route at the pyrrolic ring without an inner hydrogen, because no aromatic pathways with $4 n+2 \pi$ electrons pass via the outer route of the pyrrolic rings without an inner hydrogen. The ring current is almost equally split at the pyrrolic rings with an inner hydrogen, because the inner and the outer routes have the same number of $\pi$ electrons.

Dibenzoporphycene (XII) is aromatic sustaining a net ring-current strength of $21 \mathrm{nA} / \mathrm{T}$. The global ring current splits into an outer and inner pathway at each of the pyrrolic and benzoic rings. The current density significantly differs from that of molecule XI. XII has current pathways with $4 n+2 \pi$ electrons that can pass all carbons and nitrogens. The current strengths of the different current pathways at the pyrrolic rings are similar to the ones for the other porphycenes. The global ring current splits into a strong ring current of $16.4 \mathrm{nA} / \mathrm{T}$ via the outer route and $4.5 \mathrm{nA} / \mathrm{T}$ takes the inner route. The benzoic rings do not sustain any significant local diatropic ring current. The current strengths of the different current pathways are shown in Figure 10b.

\section{Summary and discussion}

The current pathway of porphycenes consists of a global ring current that divides into an outer and inner branch at the pyrrolic rings. At the pyrrolic rings without an inner hydrogen 


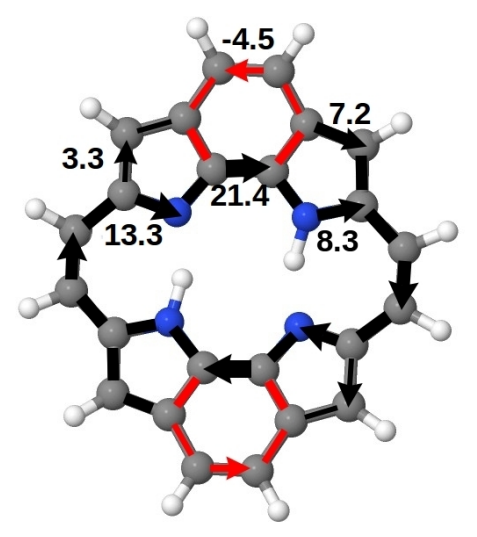

(a)

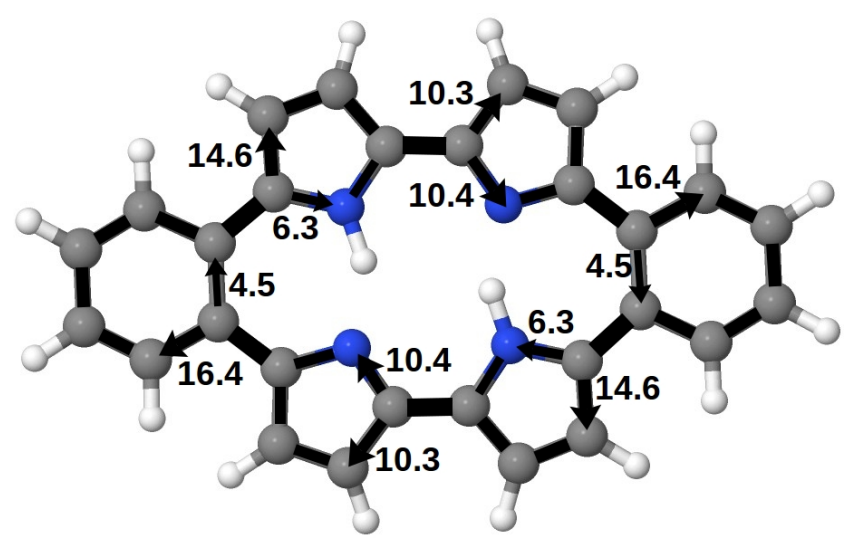

(b)

Figure 10: The calculated ring-current strengths and current pathways for (a) benzoporphycene (XI) and (b) dibenzoporphycene (XII). The figure has been made with Jmol 14.6.4 and GIMP 2.8.22. ${ }^{51,73}$

the current strengths along the two branches are about the same, whereas the ring-current strength along inner pathway via the NH groups is between one third and one half of the strength of the current that takes the outer route. The ring-current pathways and ringcurrent strengths are qualitatively the same for the studied aromatic porphycenes without any annelated benzoic rings (I, III-X). Porphyrin and these porphycenes have qualitatively the same ring-current topology. ${ }^{29,34,35}$ The pyrrolic rings of the aromatic porphycenes do not sustain any significant local ring current, which also holds for porphyrins in general. ${ }^{35}$ The pyrrolic rings are weakly aromatic in the antiaromatic dihydroporphycene (II). The annelated benzoic rings in benzoporphycene $(\mathbf{X I})$ are weakly antiaromatic sustaining local paratropic ring currents. The global diatropic ring current of molecule $\mathbf{X I}$ is $8 \mathrm{nA} / \mathrm{T}$ weaker than for porphycene (I). The current density pattern of the porphycene moiety of dibenzoporphycene (XII) is similar to the one for the other porphycenes. The current density splits into an inner and outer pathway at the benzoic rings, which do not sustain any significant local ring current of their own.

Calculations of excitation energies show that the antiaromatic dihydroporphycene (II) has a smaller optical gap than the aromatic porphycene (I), even though the HOMO-LUMO gap of molecule II is larger than for $\mathbf{I}$. 


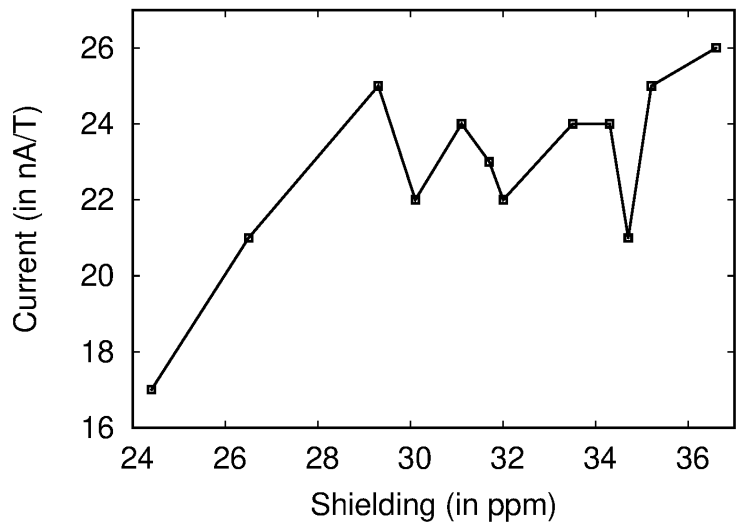

Figure 11: Calculated ring-current strength as a function of the average magnetic shieldings of the inner hydrogens. The figure has been made with Gnuplot 5.2. ${ }^{77}$

The calculated ${ }^{1} \mathrm{H}$ NMR shieldings for the inner hydrogens are plotted in Figure 11 as a function of the ring-current strength of the porphycene ring. The data used in the figure are given in the SI. The graph shows that there is no correlation between the magnetic shieldings and ring-current strengths. Thus, local contributions to the ${ }^{1} \mathrm{H}$ NMR shieldings are more important than differences in the ring-current contributions to the ${ }^{1} \mathrm{H}$ NMR shieldings, which originate from the small variations in global ring-current strengths of the studied porphycenes. The rectangular coordination center of the porphycene ring leads to strong interactions between the inner hydrogen and the neighbor nitrogen that affects the ${ }^{1} \mathrm{H}$ NMR shieldings. The experimentally observed ${ }^{1} \mathrm{H}$ NMR chemical shifts for the inner hydrogens of 2-3 ppm relatively to tetramethylsilane (TMS) ${ }^{20}$ are not due to local ring currents in the pyrrolic rings, because our current density calculations reveal that the pyrrolic rings do not sustain any significant local ring currents.

\section{Acknowledgment}

The Academy of Finland has supported this work through projects 275845, and 314821 and the MESIOS project 277579. CSC - the Finnish IT Center for Science as well as the Finnish Grid and Cloud Infrastructure (persistent identifier urn:nbn:fi:research-infras-2016072533) 
are acknowledged for computer time.

\section{Supporting Information}

Supporting Information (SI) available: The Cartesian coordinates and a data used in Figure

11. This material is available free of charge via the Internet at http://pubs.acs.org/. 


\section{References}

(1) Vogel, E.; Köcher, M.; Schmickler, H.; Lex, J. Porphycene - a novel porphin isomer. Angew. Chem. Int. Ed. 1986, 25, 257-259.

(2) Waluk, J.; Müller, M.; Swiderek, P.; Köcher, M.; Vogel, E.; Hohlneicher, G.; Michl, J. Electronic states of porphycenes. J. Am. Chem. Soc. 1991, 113, 5511-5527.

(3) Waluk, J.; Michl, J. Perimeter model and magnetic circular dichroism of porphyrin analogs. J. Org. Chem. 1991, 56, 2729-2735.

(4) Sánchez-García, D.; Sessler, J. L. Porphycenes: synthesis and derivatives. Chem. Soc. Rev. 2008, 37, 215-232.

(5) Sessler, J. L.; Brucker, E. A.; Weghorn, S. J.; Kisters, M.; Schäfer, M.; Lex, J.; Vogel, E. Corrphycene: a new porphyrin isomer. Angew. Chem. Int. Ed. 1994, 33, 2308-2312.

(6) Vogel, E.; Scholz, P.; Demuth, R.; Erben, C.; Bröring, M.; Schmickler, H.; Lex, J.; Hohlneicher, G.; Bremm, D.; Wu, Y.-D. Isoporphycene: The Fourth Constitutional Isomer of Porphyrin with an N-4 Core-Occurrence of E/Z Isomerism. Angew. Chem. Int. Ed. 1999, 38, 2919-2923.

(7) Paolesse, R.; Nardis, S.; Stefanelli, M.; Fronczek, F. R.; Vicente, M. G. H. Hemiporphycene from the Expansion of a Corrole Ring. Angew. Chem. Int. Ed. 2005, 44, 3047-3050.

(8) Richert, C.; Wessels, J. M.; Mueller, M.; Kisters, M.; Benninghaus, T.; Goetz, A. E. Photodynamic Antitumor Agents: $\beta$-Methoxyethyl Groups Give Access to Functionalized Porphycenes and Enhance Cellular Uptake and Activity. J. Med. Chem. 1994, 37, $2797-2807$.

(9) Stockert, J.; Cañete, M.; Juarranz, A.; Villanueva, A.; Horobin, R.; Borrell, J.; 
Teixidó, J.; Nonell, S. Porphycenes: facts and prospects in photodynamic therapy of cancer. Curr. Med. Chem. 2007, 14, 997-1026.

(10) Masiera, N.; Richert, L.; Mely, Y.; Waluk, J. Porphycenes as photosensitizers: Photodynamic therapy of HeLa cells. Photodiagnosis Photodyn Ther. 2017, 17, A57-A58.

(11) Oohora, K.; Kihira, Y.; Mizohata, E.; Inoue, T.; Hayashi, T. C( $\left.\mathrm{sp}^{3}\right)$-H Bond Hydroxylation Catalyzed by Myoglobin Reconstituted with Manganese Porphycene. J. Am. Chem. Soc. 2013, 135, 17282-17285.

(12) Saeki, H.; Kurimoto, O.; Nakaoka, H.; Misaki, M.; Kuzuhara, D.; Yamada, H.; Ishida, K.; Ueda, Y. Effect of crystallinity in small molecular weight organic heterojunction solar cells. J. Mater. Chem. C 2014, 2, 5357-5364.

(13) Waluk, J. Spectroscopy and Tautomerization Studies of Porphycenes. Chem. Rev. 2017, $117,2447-2480$.

(14) Vogel, E. The porphyrins from "the annulene chemist's" perspective. Pure Appl. Chem. 1993, $65,143-152$.

(15) Vogel, E.; Bröring, M.; Erben, C.; Demuth, R.; Lex, J.; Nendel, M.; Houk, K. N. Palladium Complexes of the New Porphyrin Isomers (Z)-and (E)-Isoporphycene-PdIIInduced Cyclization of Tetrapyrrolealdehydes. Angew. Chem. Int. Ed. 1997, 36, 353357.

(16) Sakow, D.; Böker, B.; Brandhorst, K.; Burghaus, O.; Bröring, M. 10-Heterocorroles: Ring-Contracted Porphyrinoids with Fine-Tuned Aromatic and Metal-Binding Properties. Angew. Chem. Int. Ed. 2013, 52, 4912-4915.

(17) Gawinkowski, S.; Walewski, Ł.; Vdovin, A.; Slenczka, A.; Rols, S.; Johnson, M. R.; Lesyng, B.; Waluk, J. Vibrations and hydrogen bonding in porphycene. Phys. Chem. Chem. Phys. 2012, 14, 5489-5503. 
(18) Wu, Y.-D.; Chan, K. W.; Yip, C.-P.; Vogel, E.; Plattner, D. A.; Houk, K. Porphyrin Isomers: Geometry, Tautomerism, Geometrical Isomerism, and Stability. J. Org. Chem. 1997, 62, 9240-9250.

(19) Ghosh, A.; Vangberg, T.; Gonzales, E.; Taylor, P. Molecular structures and electron distributions of higher-valent iron and manganese porphyrins: Density functional theory calculations and some preliminary open-shell coupled-cluster results. J. Porphyr. Phthalocyanines 2001, 5, 345-356.

(20) Sargent, A. L.; Hawkins, I. C.; Allen, W. E.; Liu, H.; Sessler, J. L.; Fowler, C. J. Global versus Local Aromaticity in Porphyrinoid Macrocycles: Experimental and Theoretical Study of "Imidacene", an Imidazole-Containing Analogue of Porphycene. Chem. Eur. J. 2003, 9, 3065-3072.

(21) Wu, J. I.; Fernández, I.; von Ragué Schleyer, P. Description of Aromaticity in Porphyrinoids. J. Am. Chem. Soc. 2013, 135, 315-321.

(22) Kim, K. S.; Sung, Y. M.; Matsuo, T.; Hayashi, T.; Kim, D. Investigation of Aromaticity and Photophysical Properties in $[18] /[20] \pi$ Porphycene Derivatives. Chem. Eur. J. 2011, 17, 7882-7889.

(23) AbuSalim, D. I.; Lash, T. D. In Pursuit of Novel Porphyrin Isomers. Aromatic Character and Relative Stability of Conjugated Tetrapyrroles with Two Neo-Confused Rings or with Mixed Neo-Confused and N-Confused Subunits. J. Phys. Chem. A 2015, 119, $11440-11453$.

(24) Steiner, E.; Fowler, P. W. The four-electron diamagnetic ring current of porphycene. Org. Biomol. Chem. 2003, 1, 1785-1789.

(25) Havenith, R. W.; Meijer, A. J.; Irving, B. J.; Fowler, P. W. Comparison of ring currents evaluated consistently at density functional and Hartree-Fock levels. Mol. Phys. 2009, 107, 2591-2600. 
(26) Aihara, J.; Nakagami, Y.; Sekine, R.; Makino, M. Validity and Limitations of the Bridged Annulene Model for Porphyrins. J. Phys. Chem. A 2012, 116, 11718-11730.

(27) Anguera, G.; Sánchez-García, D. Porphycenes and Related Isomers: Synthetic Aspects. Chem. Rev. 2017, 117, 2481-2516.

(28) Bröring, M. How Should Aromaticity Be Described in Porphyrinoids? Angew. Chem. Int. Ed. 2011, 50, 2436-2438.

(29) Fliegl, H.; Sundholm, D. Aromatic Pathways of Porphins, Chlorins and Bacteriochlorins. J. Org. Chem. 2012, 77, 3408-3414.

(30) Fliegl, H.; Özcan, N.; Mera-Adasme, R.; Pichierri, F.; Jusélius, J.; Sundholm, D. Aromatic pathways in thieno-bridged porphyrins: understanding the influence of the direction of the thiophene ring on the aromatic character. Mol. Phys. 2013, 111, 1364-1372.

(31) Valiev, R. R.; Fliegl, H.; Sundholm, D. Aromatic Pathways in Carbathiaporphyrins. J. Phys. Chem. A 2015, 119, 1201-1207.

(32) Valiev, R. R.; Cherepanov, V. N. The Influence of Benzene Rings on Aromatic Pathways in the Porphyrins. Int. J. Quant. Chem. 2013, 113, 2563-2567.

(33) Valiev, R. R.; Fliegl, H.; Sundholm, D. Predicting the degree of aromaticity of novel carbaporphyrinoids. Phys. Chem. Chem. Phys. 2015, 17, 14215-14222.

(34) Fliegl, H.; Valiev, R.; Pichierri, F.; Sundholm, D. Theoretical studies as a tool for understanding the aromatic character of porphyrinoid compounds. Chem. Modell. 2018, $14,1-42$.

(35) Sundholm, D.; Fliegl, H.; Berger, R. J. F. Calculations of magnetically induced current densities: theory and applications. WIREs Comput. Mol. Sci. 2016, 639-678.

(36) Jusélius, J.; Sundholm, D. The aromatic pathways of porphins, chlorins and bacteriochlorins. Phys. Chem. Chem. Phys. 2000, 2, 2145-2151. 
(37) Jusélius, J.; Sundholm, D. The Aromatic Character of Magnesium Porphyrins. J. Org. Chem. 2000, 65, 5233-5237.

(38) Valiev, R. R.; Fliegl, H.; Sundholm, D. New insights into magnetically induced current pathways and optical properties of isophlorins. J. Phys. Chem. A 2013, 117, 9062-9068.

(39) Fliegl, H.; Pichierri, F.; Sundholm, D. Antiaromatic Character of $16 \pi$ Electron Octaethylporphyrins: Magnetically Induced Ring Currents from DFT-GIMIC Calculations. J. Phys. Chem. A 2015, 119, 2344-2350.

(40) Valiev, R. R.; Fliegl, H.; Sundholm, D. The aromatic character of thienopyrrole-

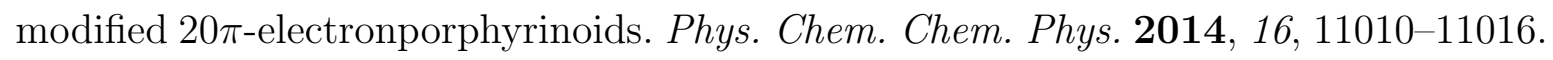

(41) Becke, A. D. Density-functional exchange-energy approximation with correct asymptotic behavior. Phys. Rev. A 1988, 38, 3098-3100.

(42) Becke, A. D. Density-functional thermochemistry. III. The role of exact exchange. J. Chem. Phys. 1993, 98, 5648-5652.

(43) Lee, C.; Yang, W.; Parr, R. G. Development of the Colle-Salvetti correlation-energy formula into a functional of the electron density. Phys. Rev. B 1988, 37, 785-789.

(44) Grimme, S.; Antony, J.; Ehrlich, S.; Krieg, H. A consistent and accurate ab initio parametrization of density functional dispersion correction (DFT-D) for the 94 elements H-Pu. J. Chem. Phys. 2010, 132, 154104.

(45) Weigend, F.; Ahlrichs, R. Balanced basis sets of split valence, triple zeta valence and quadruple zeta valence quality for $\mathrm{H}$ to Rn: Design and assessment of accuracy. Phys. Chem. Chem. Phys. 2005, 7, 3297-3305.

(46) Zhao, Y.; Truhlar, D. G. The M06 suite of density functionals for main group thermochemistry, thermochemical kinetics, noncovalent interactions, excited states, and 
transition elements: Two new functionals and systematic testing of four M06-class functionals and 12 other functionals. Theo. Chem. Acc. 2008, 120, 215-241.

(47) Becke, A. D. A new mixing of Hartree-Fock and local density-functional theories. J. Chem. Phys. 1993, 98, 1372-1377.

(48) Ahlrichs, R.; Bär, M.; Häser, M.; Horn, H.; Kölmel, C. Electronic Structure Calculations on Workstation Computers: The Program System TURBOMOLE. Chem. Phys. Letters 1989, 162, 165-169, current version: see http://www.turbomole.com.

(49) Furche, F.; Ahlrichs, R.; Hättig, C.; Klopper, W.; Sierka, M.; Weigend, F. Turbomole. WIREs Comput. Mol. Sci. 2014, 4, 91-100.

(50) Marvin 18.25, 2018, ChemAxon, http://www.chemaxon.com.

(51) GIMP: GNU Image Manipulation Program, http://www.gimp.org.

(52) Sundholm, D.; Konschin, H.; Häser, M. An Ab Initio Study of Structure and Energetics of Free-Base Bonellin- Dimethylester Isomers and Transition States. Chem. Eur. J. 1999, 5, 267-273.

(53) Langer, U.; Hoelger, C.; Wehrle, B.; Latanowicz, L.; Vogel, E.; Limbach, H.-H. ${ }^{15} \mathrm{~N}$ NMR study of proton localization and proton transfer thermodynamics and kinetics in polycrystalline porphycene. J. Phys. Org. Chem. 2000, 13, 23-34.

(54) Shibl, M. F.; Pietrzak, M.; Limbach, H.-H.; Kühn, O. Geometric H/D Isotope Effects and Cooperativity of the Hydrogen Bonds in Porphycene. ChemPhysChem 2007, 8, $315-321$.

(55) Pietrzak, M.; Shibl, M. F.; Bröring, M.; Kühn, O.; Limbach, H.-H. 1H/2H NMR Studies of Geometric H/D Isotope Effects on the Coupled Hydrogen Bonds in Porphycene Derivatives. J. Am. Chem. Soc. 2007, 129, 296-304. 
(56) Anguera, G.; Llinás, M. C.; Batllori, X.; Sánchez-García, D. Aryl nitroporphycenes and derivatives: first regioselective synthesis of dinitroporphycenes. J. Porphyr. Phthalocyanines 2011, 15, 865-870.

(57) Ostapko, J.; Nawara, K.; Kijak, M.; Buczyńska, J.; Leśniewska, B.; Pietrzak, M.; Orzanowska, G.; Waluk, J. Parent, unsubstituted hemiporphycene: synthesis and properties. Chem. Eur. J. 2016, 22, 17311-17320.

(58) Fowler, C. J.; Sessler, J. L.; Lynch, V. M.; Waluk, J.; Gebauer, A.; Lex, J.; Heger, A.; Zuniga-y Rivero, F.; Vogel, E. Metal Complexes of Porphycene, Corrphycene, and Hemiporphycene: Stability and Coordination Chemistry. Chem. Eur. J. 8, 3485-3496.

(59) Falk, H.; Chen, Q. Q. On the chemistry of pyrrole pigments, XCVI: An efficient synthesis of corrphycenes. Monatsh. Chem. 1996, 127, 69-75.

(60) Bremm, D.; Lex, J.; Hohlneicher, G. E/Z isomerism in isoporphycene and its nickel complex. Strong influence of peripheral substituents on the molecular structure. $J$. Mol. Struct. (Theochem) 2007, 802, 45-52.

(61) Wu, Y.-D.; Chan, K. W. Geometrical and electronic properties of dibenzoporphycenes. J. Mol. Struct. (Theochem) 1997, 398, 325-332.

(62) Oohora, K.; Ogawa, A.; Fukuda, T.; Onoda, A.; Hasegawa, J.-y.; Hayashi, T. mesoDibenzoporphycene has a Large Bathochromic Shift and a Porphycene Framework with an Unusual cis Tautomeric Form. Angew. Chem. Int. Ed. 2015, 54, 6227-6230.

(63) Jusélius, J.; Sundholm, D.; Gauss, J. Calculation of Current Densities using GaugeIncluding Atomic Orbitals. J. Chem. Phys. 2004, 121, 3952-3963.

(64) Fliegl, H.; Taubert, S.; Lehtonen, O.; Sundholm, D. The gauge including magnetically induced current method. Phys. Chem. Chem. Phys. 2011, 13, 20500-20518. 
(65) GIMIC, version 2.0, a current density program. Can be freely downloaded from https://github.com/qmourrents/gimic.

(66) Häser, M.; Ahlrichs, R.; Baron, H. P.; Weis, P.; Horn, H. Direct computation of 2ndorder SCF properties of large molecules on workstation computers with an application to large carbon clusters. Theoret. Chim. Acta 1992, 83, 455-470.

(67) Kollwitz, M.; Häser, M.; Gauss, J. Non-Abelian point group symmetry in direct secondorder many-body perturbation theory calculations of NMR chemical shifts. J. Chem. Phys. 1998, 108, 8295-8301.

(68) Reiter, K.; Mack, F.; Weigend, F. Calculation of Magnetic Shielding Constants with meta-GGA Functionals Employing the Multipole-Accelerated Resolution of the Identity: Implementation and Assessment of Accuracy and Efficiency. J. Chem. Theory Comput. 2018, 14, 191-197.

(69) Fliegl, H.; Jusélius, J.; Sundholm, D. Calculations of gauge-origin independent anisotropy of the current density functions. 2016, 0, (manuscript).

(70) Dimitrova, M.; Fliegl, H.; Sundholm, D. The influence of heteroatoms on the aromatic character and the current pathways of $\mathrm{B}_{2} \mathrm{~N}_{2}$-dibenzo[a,e]pentalenes. Phys. Chem. Chem. Phys. 2017, 19, 20213-20223.

(71) Ahrens, J.; Geveci, B.; Law, C. ParaView: An End-User Tool for Large Data Visualization, Visualization Handbook, Elsevier, 2005, ISBN-13: 978-0123875822, see also: http://www.paraview.org.

(72) Humphrey, W.; Dalke, A.; Schulten, K. VMD: Visual molecular dynamics. J. Mol. Graphics 1996, 14, 33-38.

(73) JMOL: an open-source Java viewer for chemical structures in 3D., http://www.jmol.org. 
(74) Valiev, R. R.; Fliegl, H.; Sundholm, D. Optical and magnetic properties of antiaromatic porphyrinoids. Phys. Chem. Chem. Phys. 2017, 19, 25979-25988.

(75) Casida, M. E.; Huix-Rotllant, M. Progress in Time-Dependent Density-Functional Theory. Annu. Rev. Phys. Chem. 2012, 63, 287-323.

(76) Furche, F.; Ahlrichs, R. Adiabatic time-dependent density functional methods for excited state properties. J. Chem. Phys. 2002, 117, 7433-7447.

(77) Williams, T.; Kelley, C.; many others, Gnuplot 5.2: an interactive plotting program. http://www.gnuplot.info/. 


\section{Graphical TOC Entry}

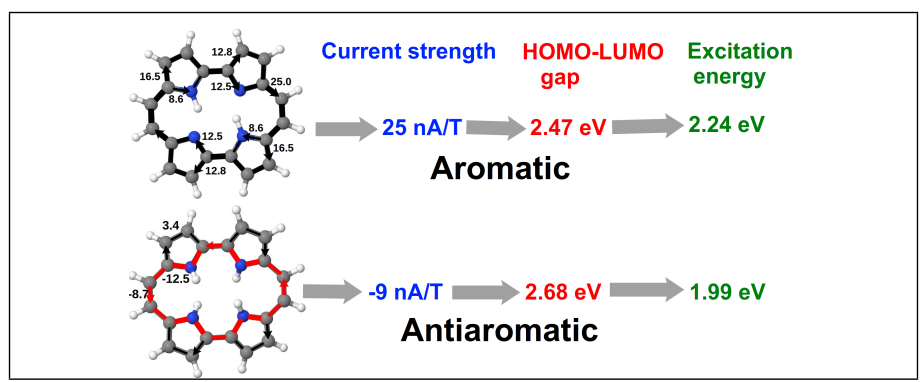

